\title{
A influência da reação presumida do outro sobre a produção de um enunciado de gênero oficial ${ }^{1}$
}

\section{The influence of the other's presumed reaction regarding the production of utterances of official genres}

Jozanes Assunção Nunes*

Universidade Federal de Mato Grosso

Cuiabá, Mato Grosso / Brasil.

RESUMO: Este artigo analisa as relações dialógicas que se engendram no Parecer CONAES n. 4/2010 que trata sobre a criação do Núcleo Docente Estruturante (NDE) no âmbito dos cursos de graduação, normatizada pela Resolução CONAES n. 01/2010. A mudança na estrutura do Parecer, a incorporação de discurso de outrem ao discurso do enunciador e o modo como este se orienta para o seu interlocutor e suas possíveis reações-respostas são especialmente observados a partir do lugar teórico e metodológico dos estudos de Bakhtin e o Círculo. A leitura dialógica do documento permitiu constatar que os sentidos do texto se constroem na fronteira entre a reação presumida dos interlocutores diante da exigência da criação de um novo órgão nas estruturas acadêmico-administrativas das Instituições de Educação Superior do Brasil e a apreciação valorativa do enunciador acerca do evento, internalizada na materialidade do enunciado.

PALAVRAS-CHAVE: Parecer CONAES; Núcleo Docente Estruturante; Relaçôes dialógicas.

ABSTRACT: This article focuses on the dialogic relations engendered in the CONAES Report 4/2010, which deals with the creation of the Structuring Professoriate Group (Núcleo Docente Estruturante - NDE) as part of undergraduate courses, regulated by the CONAES Resolution 01/2010. The changing structure of the Report, the incorporation of the other's discourse to the discourse of the speaker and how he guides himself towards his interlocutor and the possible reactions-responses of the latter are investigated herein, especially

* jozanes@globo.com

${ }^{1}$ Este trabalho é baseado em pesquisa realizada para a nossa tese de doutorado em andamento pela Pontifícia Universidade Católica de São Paulo - LAEL/PUC SP, sob a orientação da Profa. Dra. Beth Brait. 
from the theoretical and methodological perspectives of Bakhtin's Dialogic Studies. The dialogic reading of the official document allowed us to verify that the senses of the text are built on the border between the presumed reaction of interlocutors regarding the requirement of setting up a new staff in the academic and administrative structures of higher education institutions in Brazil and the process of assessing the enunciator as regards the event, internalized in the materiality of the statement.

KEYWORDS: Parecer CONAES; Structuring Professoriate Group; Dialogical Relations.

\section{Introdução}

Este artigo analisa, sob a luz da Análise Dialógica do Discurso (ADD), o Parecer n. 04, de 17 de junho de 2010, exarado pela Comissão Nacional de Avaliação da Educação Superior (CONAES), que dispõe sobre a criação do Núcleo Docente Estruturante (NDE) de cursos de graduação, normatizada pela Resolução n. 01/2010 da CONAES. O Parecer faz parte de um conjunto de documentos que compóem o corpus de nossa pesquisa de doutorado em andamento, cujo interesse analítico se pauta pela análise dialógica das vozes que constituem o discurso de professores que integram o Núcleo Docente Estruturante de cursos de Letras de uma instituição pública de ensino.

A escolha do Parecer para este estudo se justifica por sua relevância no contexto da gestão da educação superior nacional, na medida em que este deu causa à Resolução n. 1/2010 que normatiza o Núcleo Docente Estruturante de cursos de graduação no âmbito das Instituições de Educação Superior (IES), responsável pela atualização e consolidação do projeto pedagógico de curso.

Ao estudar tal documento, partimos do pressuposto, conforme a perspectiva bakhtiniana, de que em contexto polêmico como o que analisamos, a produção de um enunciado é pautada por uma presumida reação-resposta de seus destinatários. Nessa ótica, o objetivo deste trabalho é analisar as relações dialógicas que se engendram no referido Parecer, discorrendo sobre a influência da reação presumida dos interlocutores sobre a forma composicional do enunciado e sobre o modo como a posição axiológica do autor foi construída ao longo do texto.

Para isso, dividimos o artigo em quatro seçôes. Na primeira, discorremos sobre o embasamento teórico-metodológico que ancora a pesquisa, discutindo alguns princípios, noçōes e categorias bakhtinianas. Nessa seção, descrevemos também, inicialmente, os procedimentos 
metodológicos de abordagem dos fenômenos discursivos por nós recortados. $\mathrm{Na}$ segunda, discutimos sobre as condições de produção do Parecer, concebendo-o bakhtiniamente como enunciado concreto, em que a situação e o meio social determinam a estrutura da sua enunciação. Discutimos, ainda, sobre a mudança na composição estrutural do Parecer, tomando por base o regimento interno da CONAES e pareceres de outro órgão colegiado do MEC. Na terceira, com base nas reflexões apresentadas nas seções anteriores, centramo-nos de modo mais direto na análise dialógica do Parecer na sua totalidade, procurando, entre outras questões, ressaltar as estratégias discursivo-argumentativas, utilizadas na escrita do texto, com destaque para a noção de discurso já-dito e discurso-resposta futuro. Por fim, concluímos nossa trajetória com as considerações finais.

\section{Recorte teórico-metodológico}

Ao optarmos por um trabalho metodológico, analítico e interpretativo de um texto/enunciado de gênero elevado, oficial, como o parecer, a perspectiva bakhtiniana se apresenta perfeitamente apropriada. Somos conscientes de que, como afirma Brait (2008), Bakhtin e o Círculo jamais postularam "um conjunto de preceitos sistematicamente organizados para funcionar como perspectiva teórico-analítica fechada” (p. 09), mas nos deixaram "um corpo de conceitos, noçôes e categorias que especificam a postura dialógica diante do corpo discursivo, da metodologia e do pesquisador" (p. 29). Com base nesse fio norteador, cabe ao pesquisador desbravar o caminho analítico, seguindo os princípios metodológicos da abordagem sociológica da linguagem apresentada por Bakhtin/Volochínov (2014). Tais princípios conferem uma abordagem interdisciplinar na análise de enunciados, ao considerar uma estreita relação entre os elementos linguísticos e extralinguísticos.

Sob essa perspectiva, formulamos nossa trajetória de pesquisa a partir da orientação de Bakhtin/Volochínov (2014, p. 129), pela qual primeiro é necessário compreender a "língua viva" que se dá numa situação histórica, concreta, observando o gênero a que pertence o texto, para, por fim, realizar a análise das "formas da língua na sua interpretação linguística". Assim, o estudo se efetivou em duas etapas correlacionadas entre si: discussão sobre as características do Parecer (condições de produção e forma composicional) e análise dialógica do enunciado na sua totalidade, englobando as discussões anteriores. Como categoria de análise e interpretação, levantamos os 
conceitos de enunciado, discurso/ relações dialógicas (com ênfase nas noções de discurso já-dito e discurso-resposta futuro), correlacionados à noção de gêneros discursivos, seguindo o seguinte percurso:

1) Interpretação do modo como o autor percebe seu interlocutor e suas possíveis reaçōes-respostas, a partir da observação da estrutura composicional do enunciado e da forma como foi construído o posicionamento axiológico do enunciador;

2) Identificação e análise das vozes e discursos convocados para construção da orientação axiológica do enunciador;

3) Identificação e interpretação das marcas do autor que caracterizam argumentos de autoridade;

4) Interpretação da orientação valorativa do sujeito enunciativo diante do que é dito no texto.

Este trabalho se insere, portanto, na perspectiva teórico-metodológica da Metalinguística (ciência criada por BAKHTIN, 2013), também denominada Translinguística (por TODOVOV, 1981) ou Análise Dialógica do Discurso (BRAIT, 2008), onde buscamos analisar o Parecer CONAES n. 04/2010 como enunciado sócio-historicamente situado. Consoante aos preceitos de Bakhtin e o Círculo, compreendemos que esse enunciado está orientado por um contexto enunciativo, constituído de elementos como o papel do sujeito-autor, as posições assumidas, as especificidades da esfera discursiva e o momento sócio-histórico em que foi construído. Além disso, entendemos que, como afirmam Bakhtin (2011) e Medviédev (2012), todo enunciado está voltado para o destinatário o qual influenciará a sua produção. A partir desse contexto, passemos, então, a um breve recorte sobre os pressupostos que iremos nos apoiar para o desenvolvimento desta pesquisa.

\subsection{A perspectiva bakhtiniana para análise do Parecer}

A essência da linguagem, na perspectiva bakhtiniana, é o fenômeno social da interação verbal, de qualquer tipo, sendo o diálogo face a face apenas um destes muitos tipos. Nesse contexto, a linguagem é entendida como atividade, como conjunto de práticas socioculturais, como uma gama incrivelmente intricada de formas sociais de comunicação, pois permite ao homem ligar-se aos outros homens, às suas características naturais e a seus determinantes sociais. Em outras palavras, ela "é concebida de um ponto 
de vista histórico, cultural e social que inclui, para efeito de compreensão e análise, a comunicação efetiva e os sujeitos e discursos nela envolvidos" (BRAIT e MELO, 2012, p. 65).

Além disso, a enunciação, o ato da fala, é de natureza social, resultado da interação entre dois indivíduos socialmente organizados, não podendo ser considerado como individual no sentido estrito do termo. Enunciar é, pois, dar vida à palavra, é a materialização da palavra como signo. A realidade toda da palavra, afirma Bakhtin/Volochínov (2014, p. 36-37), "é absorvida por sua função de signo", pois ela "é o modo mais puro e sensível de relação social”. É por meio dela que acontece a maior parte das práticas sociais. É ela quem carrega as instituições, as ideologias, as crenças e é ela quem "revela as formas ideológicas gerais da comunicação semiótica”. Isso significa que a palavra está em todas as esferas da criação ideológica, em todos os domínios das relações sociais, além de ser o material do discurso interior. Por fim, ela é o "signo ideológico por excelência".

Na perspectiva bakhtiniana, o signo é tanto parte de uma realidade como também reflete e refrata outra realidade que lhe é exterior. E é porque os signos refletem e refratam o real que um mesmo dado da realidade pode ser compreendido de diferentes maneiras pelas diferentes esferas de comunicação discursiva (ou da criatividade ideológica). A esse respeito, Bakhtin/Volochínov (2014, p. 47-48) esclarece que classes sociais distintas utilizam o mesmo sistema de comunicação e que, consequentemente, os signos se transformam em arena de confrontação de diferentes índices de valor. Nesse embate, conforme o teórico, "a classe dominante tende a conferir ao signo ideológico um caráter intangível e acima das diferenças de classe, a fim de abafar ou de ocultar a luta dos índices sociais de valor que aí se trava, a fim de tornar o signo monovalente". ${ }^{2}$ Sobre essa questão, Ponzio (2011) elucida que, para o teórico russo, os signos ideológicos refletem e refratam a realidade segundo projeçôes de classes diferentes que tentam manter as relações sociais de produção ou, ao contrário, propõem-se como instrumento de luta, de questionamento daquilo que é apresentado como natural, certo,

\footnotetext{
${ }^{2}$ Vianna (2010) observa que essa posição de Bakhtin/Volochínov está em consonância com a de Marx e Engels presente na obra $A$ ideologia alemã. $\mathrm{O}$ autor reconhece a convergência de conceitos basilares entre as formulações dos autores, mas ressalta que há notáveis avanços no que tange às questóes referentes à linguagem na obra Marxismo e filosofia da linguagem, de Bakhtin/Volochínov.
} 
unívoco. Nessa direção, o autor apresenta a seguinte compreensão de ideologia para Bakhtin:

Portanto, podemos dizer que ideologia, para Bakhtin, não é uma simples "visão de mundo", mas uma projeção social, no sentido em que a define Rossi-Landi: a mesma pode reproduzir a ordem social existente e manter como "definitivos" e "naturais" os sentidos que as coisas têm em um determinado sistema de relações de produção ou, ao contrário, discutir e subverter na prática essas relaçōes e sua articulação sígnico-ideológica, quando impedem o desenvolvimento das forças de produção. Numa realidade social que apresente contradiçôes de classe, as ideologias respondem a interesses diferentes e contrastantes (PONZIO, 2011, p. 116).

Sob essa ótica, a ideologia, ${ }^{3}$ na perspectiva bakhtiniana, não tem apenas o caráter de mascaramento e falseamento do real; tem, também, o sentido de representaçôes verdadeiras, objetivas, devido à existência de forças outras que povoam o universo ideológico. Isso se deve ao fato de a ideologia ser constituída de signos, os quais podem "distorcer a realidade, ser-lhe fiel, ou apreendê-la de um ponto de vista específico" (BAKHTIN/ VOLOCHÍNOV, 2014, p. 32). O autor italiano destaca ainda que, segundo o pensamento bakhtiniano, no signo ideológico, está sempre presente uma dimensão valorativa, que faz com que o mesmo não seja mera expressão de uma ideia, mas a expressão de uma tomada de posição determinada, de uma práxis efetiva (PONZIO, 2011).

$\mathrm{O}$ que se observa até aqui é que as noções de signo/linguagem e ideologia estão intrinsecamente ligadas, tendo em vista que "tudo que é ideológico é um signo. Sem signos não existe ideologia" (BAKHTIN/ VOLOCHÍNOV, 2014, p. 31, grifos do autor). Uma vez estabelecida a relação constitutiva entre tais noções, constatamos a postulação da dimensão valorativa dos enunciados, não havendo, desse modo, enunciados neutros. Conforme acentua Faraco (2009), qualquer enunciado é sempre ideológico. E ideológico em dois sentidos, considerando que se dá no interior de uma

\footnotetext{
${ }^{3}$ Ponzio (2011) destaca que a noção de ideologia ocupa um lugar essencial nos estudos do Círculo. Entretanto, não há uma única definição para o termo, podendo indicar diferentes formas de cultura, os sistemas superestruturais, como a arte, o direito, a religião, a ética, o conhecimento científico, etc.
} 
das áreas da atividade intelectual humana e expressa sempre uma posição avaliativa.

Assim, não podemos desconsiderar essa realidade ao estudar o Parecer da CONAES, entendendo que, como enunciado concreto e real da comunicação discursiva, ele está inerentemente associado à instância institucional em que foi produzido e, por isso, reflete e refrata seus valores ideológicos, remetendo a uma posição axiológica.

É importante destacar que a análise de um enunciado concreto deve passar pela análise da concretude pela qual e na qual se realizou. Nessa perspectiva, a tarefa intelectualmente desafiadora proposta por este trabalho é desvelar não apenas as formas linguísticas que entram em cena no ato da enunciação, mas também analisar os aspectos extralinguísticos do enunciado, numa perspectiva dialógica, pois, como afirma Voloshinov (1926, p. 5), "na vida, o discurso verbal é claramente não autossuficiente. Ele nasce de uma situação pragmática extraverbal e mantém a conexão mais próxima possível com essa situação".

Voloshinov (1926, p. 7) afirma também que "o horizonte comum do qual depende um enunciado pode se expandir tanto no espaço como no tempo". Isso remete a um dos aspectos da dimensão extraverbal do enunciado: o cronotopo, "que trata de uma produção da história. Designa um lugar coletivo, espécie de matriz espaço-temporal de onde as várias histórias se contam ou se escrevem" (AMORIM, 2008, p. 105). Isso significa, no contexto deste trabalho, compreender o Parecer CONAES n. 04/2010 como um "evento" social e histórico, ressoando seu tempo e contextos atuais e seus usos passados.

No que se refere aos outros participantes da interação socioverbal, a dialogicidade do enunciado desempenha o papel central, devendo ser entendida como relações de sentido que decorrem da responsividade inerente a todo e qualquer enunciado, em que cada enunciado é visto como uma resposta aos enunciados precedentes de determinada esfera de comunicação, situada num complexo quadro de relações socioculturais.

Entender o enunciado nessa perspectiva nos leva ao conceito bakhtiniano de discurso que, fundido em forma de enunciado, pertencente a um determinado sujeito, se constitui das muitas vozes interiorizadas em múltiplas relações dialógicas. No dizer de Bakhtin (2011, p. 294-295): 
Nosso discurso, isto é todos os nossos enunciados (inclusive as obras criadas) é pleno de palavras dos outros, de um grau vário de alteridade ou assimilabilidade, de um grau vário de aperceptibilidade e de relevância. Essas palavras dos outros trazem consigo a sua expressão o seu tom valorativo que assimilamos, reelaboramos, e reacentuamos.

Assim, os enunciados são construídos a partir de outros discursos já-ditos - de que o sujeito se apropria, assimila, transforma, recusa, altera, critica, concorda ou discorda, bem como de discurso-resposta futuro - reação ativa, verbal ou não, do interlocutor, que o falante leva em conta, "pressente-a e baseia-se nela" (BAKHTIN, 2014, p. 89). Essa dinâmica é o verdadeiro ambiente de um enunciado, visto que o objeto do discurso, "por assim dizer, já está ressalvado, contestado, elucidado e avaliado de diferentes modos; nele se cruzam, convergem e divergem diferentes pontos de vista, visões de mundo, correntes" (BAKHTIN, 2011, p. 300).

A palavra apropriada é própria na medida em que é usada em contextos específicos, com uma intenção discursiva definida. Todavia, mesmo sendo atualizada em contextos únicos, ainda que singular, a palavra é sempre novamente orientada dialogicamente a um interlocutor real ou virtual, presente ou ausente, próximo ou distante a outros discursos já proferidos e antecipados. Sob essa perspectiva, todo enunciado está endereçado para um destinatário e essa realidade vai determinar significativamente as suas características, tendo em vista que ele é produzido sob a influência da reaçãoresposta desse destinatário:

Ao falar, sempre levo em conta o fundo aperceptível da percepção do meu discurso pelo destinatário; (...) levo em conta as suas concepções e convicçóes, os seus preconceitos (do meu ponto de vista), as suas simpatias e antipatias - tudo isso irá determinar a ativa compreensão responsiva do meu enunciado por ele (BAKHTIN, 2011, p. 302).

Além desse modo de funcionamento real da linguagem, há também outra perspectiva dialógica que consiste na incorporação do discurso alheio ao discurso do sujeito enunciador. É o discurso citado, que, conforme Bakhtin/Volochínov (2014, p. 150), "é o discurso no discurso, a enunciação na enunciação, mas é, ao mesmo tempo, um discurso sobre o discurso, uma enunciação sobre a enunciação" (grifos do autor). Esse tipo de discurso é constituído por esquemas linguísticos, tais como discurso direto, discurso indireto e discurso indireto livre. 
O discurso marcado abertamente, com estabelecimento de fronteiras definidas entre o discurso narrativo e o discurso citado, caracteriza-se discurso direto. Esse esquema cria, no enunciado, um efeito de sentido de verdade. $\mathrm{O}$ discurso indireto consiste numa forma de apreensão ativa, analisadora do discurso de outrem. Os elementos emocionais e afetivos do discurso não são literalmente transpostos a esse tipo de esquema, na medida em que não são expressos no conteúdo, mas nas formas da enunciação. $\mathrm{O}$ discurso indireto livre é o caso mais bem fixado sintaticamente de "convergência interferente de dois discursos com diversa orientação do ponto de vista da entoação" (BAKHTIN/VOLOCHÍNOV, 2014, p. 176). Nessa forma de apreensão da palavra de outrem, a voz do falante/autor e a voz do "outro" dialogam, constituindo um mesmo enunciado com duas entoações de duas vozes distintas em torno de uma mesma temática.

É na dialogia possível da prática que estão inseridos os gêneros do discurso ou os diversos tipos de enunciados, relativamente estáveis do ponto de vista temático, composicional e estilístico, caracterizados pelos contextos nos quais são utilizados. Esses gêneros possuem similaridades e obedecem a certas convenções linguísticas e discursivas, reconhecíveis na comunidade (BAKHTIN, 2011). É o caso do parecer que, como qualquer gênero, reflete as condições específicas e as finalidades da esfera em que é produzido.

Assim sendo, o surgimento de um gênero discursivo numa dada esfera depende do tipo de atividade nela desenvolvida, sendo que, quanto mais complexa é uma sociedade, mais complexos e em maior número os gêneros são nela construídos (BAKHTIN, 2011). Não obstante, vale destacar que é na especificidade de cada esfera de comunicação que os gêneros também desaparecem ou se modificam, cumprindo certas funções sociocomunicativas.

Cada gênero discursivo tem a sua concepção de destinatário e tanto a composição quanto o estilo dependem de saber a quem se destina o enunciado, como o enunciador percebe e representa para si os seus destinatários, bem como qual é a força e a influência deles no enunciado. Esse destinatário, de acordo com Bakhtin (2011, p. 301), pode ser

um participante-interlocutor direto do diálogo cotidiano, pode ser uma coletividade diferenciada de especialistas de algum campo especial da comunicação cultural, pode ser um público mais ou menos diferenciado, um povo, os contemporâneos, os correligionários, os adversários e inimigos, o subordinado, o chefe, um inferior, um superior, uma pessoa 
íntima, um estranho, etc.; ele também pode ser um outro totalmente indefinido, não concretizado (em toda sorte de enunciados monológicos de tipo emocional) (BAKHTIN, 2011, p. 301).

Em se tratando de parecer emitido por colegiado, geralmente, os destinatários imediatos sãos os pares do relator do enunciado. Esse tipo de parecer somente surtirá efeitos se aprovado pelo plenário, caso em que deve ser explicitado no documento (KASPARY, 2007). A partir da sua função social e suas condições de produção, podemos dizer que esse gênero é a manifestação de um órgão sobre assuntos submetidos à sua consideração, com indicação de solução favorável ou desfavorável, precedida de necessária justificação, com base em dispositivos legais (KASPARY, 2007). Percebese, assim, nesse gênero, um processo de produção que prevê uma ação de sustentação das afirmaçōes realizadas por meio de fundamentação consistente do relator, a fim de convencer o seu interlocutor.

Sob esse olhar, cabe ainda destacar que, de acordo com a perspectiva bakhtiniana, um gênero se define, primeiramente, por seu propósito comunicativo e não por sua forma linguística. Entretanto, isso não significa que devemos desconsiderar a configuração reconhecível pelos falantes, na identificação dos gêneros, visto que a configuração linguísticodiscursiva estável de cada gênero é um aspecto relevante na sua constituição (BAKHTIN, 2011). É essa face estável que permite a intercomunicação e que garante um processo de inteligibilidade mínimo. Devido a isso, não é preciso, em cada interação, construir um novo quadro cognitivo acerca do gênero utilizado. É importante ressaltar, todavia, que devemos ver os gêneros como tipos dinâmicos e não como modelos estanques, nem estruturas rígidas. Mesmo os gêneros elevados, oficiais, admitem mudanças, estão abertos às condições concretas de uso (BAKHTIN, 2011), como veremos neste trabalho.

Por fim, na análise das relações dialógicas de quaisquer espécies, o lugar teórico da noção de gênero configura-se imprescindível, tendo em vista que, como postula Bakhtin (2011, p. 264), todo trabalho de investigação de um material linguístico concreto opera inevitavelmente com enunciados concretos relacionados a diferentes campos da atividade humana e da comunicação "de onde os pesquisadores haurem os fatos linguísticos de que necessitam”. Desconsiderar essa realidade pode deformar a historicidade da investigação e debilitar as relações da língua com a vida. Partindo, então, desse pressuposto, passemos à discussão do Parecer CONAES n. 
04/2010, discorrendo, primeiramente, sobre suas condições de produção e reacentuação da sua estrutura composicional.

\section{Características do Parecer CONAES n. 04/2010: condições de produção e "relativa estabilidade" do enunciado}

Antes do nosso estudo sobre as relações dialógicas que se engendram no Parecer n. 04/2010, ideologicamente produzido pela Comissão Nacional de Avaliação da Educação Superior (CONAES), analisando-o na sua totalidade, faz-se necessária uma breve discussão sobre as condições de produção do enunciado e especificidade da sua forma composicional.

A CONAES é um órgão colegiado de coordenação e supervisão do Sistema Nacional de Avaliação da Educação Superior (SINAES), ${ }^{4}$ vinculado ao Gabinete do Ministério de Educação, instituído pela Lei 10.861, de 14 de abril de 2004. Com importante papel no acompanhamento e garantia de legitimidade do SINAES, a comissão, de acordo com a referida Lei, tem as atribuições de propor e avaliar as dinâmicas, procedimentos e mecanismos da avaliação institucional, de cursos e de desempenho dos estudantes; estabelecer diretrizes para organização e designação de comissões de avaliação, analisar relatórios, elaborar pareceres e encaminhar recomendações às instâncias; submeter anualmente à aprovação do Ministro da Educação a relação dos cursos a cujos estudantes será aplicado o Exame Nacional de Desempenho dos Estudantes (ENADE), entre outras (BRASIL, 2004).

Posto isto, as dimensões valorativas e ideológicas dos enunciados produzidos por esse órgão referem-se à avaliação institucional e de cursos de graduação, Exame Nacional do Desempenho dos Estudantes e instrumentos de informaçōes de cursos. Com base no inciso I, artigo $6^{\circ}$ da Lei 10.861/2004 (SINAES), que confere à CONAES a competência para "propor e avaliar as dinâmicas, procedimentos e mecanismos da avaliação institucional, de cursos e de desempenho dos estudantes", a comissão elaborou o Parecer n. 4/2010, que tem como conteúdo temático a criação do Núcleo Docente Estruturante no âmbito dos cursos de graduação.

\footnotetext{
${ }^{4}$ O Sistema Nacional de Avaliação da Educação Superior - SINAES, instituído pela Lei n. 10.861, de 14 de abril de 2004, vem sendo desenvolvido no Brasil como uma política pública de avaliação, tendo por finalidades a melhoria da qualidade da educação superior (BRASIL/MEC, 2004).
} 
Considerando o aspecto da produção do documento, podemos observar duas dimensões de escritas que ocorreram num mesmo espaço temporal: a escrita do Parecer, produzida no dia 17 de junho de 2010 e a escrita da Resolução n. 01, decorrente do referido Parecer, elaborada no mesmo dia. Isso se deu porque, conforme Regimento Interno da CONAES (BRASIL, 2005), o Colegiado manifesta-se pelos seguintes gêneros: (i) Indicação - ato propositivo, subscrito por um ou mais membros, contendo sugestão justificada de realização de estudo sobre qualquer matéria de interesse da CONAES; (ii) Parecer - ato pelo qual o Colegiado pronunciase sobre matéria de sua competência; e (iii) Resolução - ato decorrente de parecer, destinado a estabelecer normas a serem observadas sobre matéria de competência da CONAES.

Assim, com base no disposto no Parecer CONAES n. 04/2010, bem como na Portaria 147, de 02 de fevereiro de 2007, a Comissão Nacional de Avaliação da Educação Superior (CONAES) elaborou a Resolução n. 01, de 17 de junho de 2010, que normatiza o Núcleo Docente Estruturante (NDE) no âmbito dos cursos de graduação. De acordo com a referida Resolução, o NDE constitui-se de um grupo de docentes com atribuições acadêmicas de acompanhamento, atuante no processo de concepção, consolidação e contínua atualização do projeto pedagógico do curso. Deve ser constituído por professores pertencentes ao corpo docente do curso, que exerçam liderança acadêmica no âmbito do curso, percebida na produção de conhecimentos na área, no desenvolvimento do ensino e em outras dimensões entendidas como importantes pela instituição.

No que se refere a pareceres, o Regimento Interno da CONAES estabelece que esse gênero deve constar de Relatório, voto fundamentado do Relator e Conclusão do Colegiado, seguindo de votos divergentes e declarações de voto (BRASIL, 2005). ${ }^{5}$ Nessa ótica, o processo de produção do enunciado é marcado pela dialogicidade e alteridade, visto que é necessária a antecipação da posição do outro (primeiramente, dos pares, tendo em vista que o enunciado deve ser submetido à apreciação valorativa do colegiado; depois dos sujeitos das instâncias acadêmicas onde o enunciado circulará) para refutá-la com base em dispositivos legais.

${ }^{5}$ No Regimento Interno da CONAES, o parecer foi o único gênero que mereceu atenção do órgão, no sentido de estabelecer sua estrutura (BRASIL/MEC, 2005). 
Não obstante, na estrutura composicional do parecer em análise, constatam-se apenas o título "Parecer CONAES n. 4 de 17 de junho de 2010, sobre o Núcleo Docente Estruturante - NDE" e um texto corrido, de aproximadamente duas páginas e meia, contendo as posições ideológicodiscursivas da CONAES acerca da relevância da criação do NDE nos cursos de graduação. No final, há um texto brevíssimo: "Parecer aprovado pela CONAES em reunião ordinária, ocorrida em 17 de junho de 2010”, seguido da assinatura da presidente da comissão. Quem enuncia não é um relator, mas sim o colegiado como um todo, como veremos na seção seguinte. Devido a isso, não contém, no texto, o voto fundamentado do relator, a conclusão do colegiado, os votos divergentes, nem as declarações de voto, conforme estabelecido no Regimento Interno (BRASIL, 2005). Como se percebe, consoante ao que afirma Bakhtin (2011), mesmo pertencendo a um gênero bastante estandardizado, o enunciado em estudo sofreu uma adequação.

Em decorrência do caráter dialógico e social da linguagem, a estrutura do parecer, preestabelecida pelo Regimento da CONAES, se aproxima da dos pareceres do Conselho Nacional de Educação (CNE), órgão colegiado integrante do Ministério da Educação, instituído em 1995 com a finalidade de colaborar na formulação da Política Nacional de Educação e exercer atribuiçôes normativas, deliberativas e de assessoramento ao Ministro da Educação (BRASIL/MEC, 1995). Fazendo uma comparação entre os pareceres desses dois órgãos colegiados (CONAES e CNE), percebemos mais claramente os pontos de fuga do Parecer CONAES n. 04/2010, ${ }^{6}$ quanto à sua estrutura composicional.

Os Pareceres do Conselho Nacional de Educação (CNE), em geral, apresentam:7 (i) Timbre da instituição concedente (MEC e seu órgão normativo, deliberativo, de supervisão e de assessoramento - o CNE); (ii) Cabeçalho, contendo: interessado pela manifestação do Conselho; assunto da

\footnotetext{
${ }^{6}$ Faz-se aqui importante mencionar que o único Parecer divulgado pela CONAES em seu site, na seção “atas, pareceres e resoluções”, é o Parecer CONAES n. 04/2010. Disponível em: <http://portal.mec.gov.br/index.php?option=com_ content\&view=article\&id=15712\&Itemid=1093>. Acesso em: $1 \mathrm{dez} .2014$.

${ }^{7}$ As características dos Pareceres do CNE apresentadas se baseiam na observação desse gênero, disponibilizado para o público no site do Ministério da Educação. Disponível em: <http://portal.mec.gov.br/index.php?option=com_content\&id=12991\&Itemid=866> . Acesso em: 1 dez. 2014.
} 
solicitação; relator(res) responsável(is) pela análise e avaliação do assunto; número do processo consultado pelo(s) relator(es); número do Parecer seguido do ano; Colegiado que tramitou o parecer e data da aprovação do enunciado; (iii) Relatório fundamentado; (iv) Voto do(s) relator(es) com a avaliação final, seguido de local, data e assinatura(s); (v) Decisão da Câmara (ou do Conselho Pleno) - texto breve aprovando o voto do(s) Relator(es), seguido de local, data e assinatura do presidente. Nesse Conselho, o parecer é dirigido, primeiramente, aos membros do colegiado para a sua apreciação valorativa e posterior aprovação ou reprovação.

Considerando o Parecer n. 04/10 da CONAES e os pareceres do CNE, além da diferença que há entre eles no aspecto composicional, há também diferenças quanto à intenção discursiva (BAKHTIN, 2011). Os pareceres do CNE, em geral, visam apresentar um ponto de vista, um encaminhamento fundamentado sobre uma matéria submetida à consideração do órgão (CURY, 2006, p. 51).

Diferentemente, no Parecer CONAES n. 04/2010, objeto deste estudo, não há uma tomada de posição acerca de um tema submetido à consideração da comissão, mas sim a ação ou resultado de determinar(se), qual seja: a criação do Núcleo Docente Estruturante, cujo interesse sobre a questão defendida parte do próprio colegiado, como veremos na seção da análise dialógica do Parecer. O enunciado não se dirige aos pares, como previsto no Regimento, mas sim aos segmentos das comunidades acadêmicas, entre outros interlocutores, cuja interação se apresenta numa relação de imposição. Cabe destacar que tal enunciado, hoje, juntamente com a Resolução CONAES n. 1/2010, compõe o conjunto de legislação que sustenta procedimentos e critérios de aspectos específicos que estão presentes nos processos avaliativos, consultados pelas instâncias acadêmicas e por avaliadores do MEC in loco.

A finalidade discursiva, com vistas a atingir um destinatário específico ocasionou, portanto, a alteração na forma composicional do documento, o qual não apresenta a estrutura descrita no Regimento Interno do órgão. Nesse sentido, o enunciado foi produzido visando à reação-resposta ativa desse destinatário diante da exigência da criação de um Núcleo Docente Estruturante de cursos no âmbito das Instituições de Educação Superior.

A interação discursiva do Parecer n. 04/2010 é mediada ideologicamente pelo Ministério da Educação e sua circulação ocorre na esfera oficial da gestão e regulação dos cursos de graduação. A forma de sua 
produção, os discursos já-ditos que compõem o enunciado e os discursosrespostas futuros que se anteciparam à recepção responsiva dos interlocutores, a fim de que as ideias instauradas no enunciado tornassem aceitas, é o que abordaremos na seção seguinte.

\section{O Parecer CONAES n. 04/2010: uma análise dialógica}

A partir das ideias expostas nas duas últimas seções, passemos para a análise dialógica do Parecer n. 04, de 17 de junho de 2010, exarado pela Comissão Nacional de Avaliação da Educação Superior (CONAES). Analisar esse enunciado pelo viés bakhtiniano é compreender que quando estudamos qualquer enunciado "com mais profundidade em situaçôes concretas de comunicação discursiva, descobrimos toda uma série de palavras do outro semilatentes e latentes, de diferentes graus de alteridade" (BAKHTIN, 2011, p. 299). Além disso, de acordo com o teórico russo, no seu empreendimento enunciativo, o sujeito discursivo imagina uma atitude responsiva de seus prováveis leitores (BAKHTIN, 2011). Em consonância com tais colocações, analisaremos o Parecer CONAES n. 04/2010, levando em consideração a questão dialógica nele engendrada.

Produzido, dialogicamente, na interação verbal e real da "língua viva", o parecer em análise, como vimos, se inicia com um título que contempla o significado global do texto: "Parecer CONAES n. 4 de 17 de junho de 2010, sobre o Núcleo Docente Estruturante - NDE”. Tal título evidencia o lugar social, o tempo e a temática do enunciado, marcando o gênero a que o texto pertence. Já no início, logo após o título, constatamos a preocupação do enunciador do discurso com a opinião e a avaliação presumidas de seus interlocutores diante da exigência da criação do Núcleo Docente Estruturante (NDE) no âmbito dos cursos de graduação:

O Núcleo Docente Estruturante - NDE foi um conceito criado pela Portaria n. 147, de 2 de fevereiro de 2007, com o intuito de qualificar o envolvimento docente no processo de concepção e consolidação de um curso de graduação. Neste instrumento legal, em seus artigos $2^{\circ}$, inciso IV, referente à autorização de cursos de Medicina, e $3^{\circ}$, inciso II, referente à autorização de cursos de Direito, o NDE é caracterizado por ser "responsável pela formulação do projeto pedagógico do curso - PPC, sua implementação e desenvolvimento, composto por professores: a) com titulação em nível de pós-graduação stricto sensu; b) contratados em regime de trabalho que assegure preferencialmente dedicação plena ao curso; e c) com experiência docente". 
Ocorre que o enunciador discursivo vai defender a ideia da criação de um novo órgão acadêmico-administrativo dentro das Instituições de Educação Superior (IES), denominado Núcleo Docente Estruturante. Todavia, pautando-se pela alteridade e imaginando uma atitude responsiva de seus interlocutores (aqueles que criariam o núcleo: segmentos da comunidade acadêmica), logo na introdução do texto, o sujeito discursivo reenuncia o discurso já-dito na Portaria Ministerial n. 147/2007, emitida pelo Ministro da Educação. O conteúdo temático da Portaria trata especificamente da complementação da instrução dos pedidos de autorização de cursos de graduação em Direito e Medicina, fazendo menção à exigência do "Núcleo Docente Estruturante responsável pela formulação do projeto pedagógico do curso, sua implementação e desenvolvimento". O Núcleo Docente Estruturante seria, assim, exigido legalmente dos cursos de Direito e Medicina.

Para estender essa obrigatoriedade a todos os cursos de graduação (licenciatura e bacharelado, incluindo os cursos superiores de tecnologia em qualquer fase do processo de regulação), o sujeito discursivo constrói ideologicamente seu discurso correlacionando-o com o posicionamento do Ministério da Educação (MEC) expresso na portaria. Sob essa ótica, não é só o sujeito-autor do Parecer que defende esse ponto de vista, mas, primeiramente, o Ministério da Educação, que, aliás, se manifesta diretamente no texto, por meio do discurso relatado direto (BAKHTIN/ VOLOCHÍNOV, 2014).

O discurso dessa voz institucional é trazido para o Parecer como argumento, entrando no enunciado intencionalmente como coautoria, com vistas a convencer os interlocutores de que a constituição de um grupo de professores titulados e dedicados ao desenvolvimento dos cursos é fundamental para melhorar a sua qualidade. $\mathrm{O}$ acúmulo de autoria quanto à ideia de criação do Núcleo Docente Estruturante no âmbito das Instituições de Educação Superior (IES) é fundamental no enunciado, considerando tratar de uma exigência que interferiria diretamente na organização das instituições públicas e privadas, cuja composição do órgão implicaria em aumento de custos. Por mais que a posterior homologação do Parecer pelo Ministro da Educação possa significar reconhecer como legítimo o que nele é dito, trazê-lo para o texto diretamente é uma ação dialógica que contribui para sustentar a opinião nele defendida. Com o discurso direto, ouve-se, no Parecer, no mínimo, três sujeitos discursivos e suas mútuas relações 
dialógicas: o sujeito-autor do texto, o Ministério da Educação e o leitor (BAKHTIN, 2011).

Como vimos na seção anterior, no texto, não há a identificação de relatores ou de comissão composta por membros do colegiado como enunciadores do discurso, responsáveis pelo enunciado que deveria ser submetido à apreciação valorativa dos demais membros, conforme Regimento da CONAES. O que é dito no Parecer corresponde à posição axiológica de um consenso de opinióes do colegiado, como uma voz coletiva que cria e sustenta a unidade do enunciado, além da voz do MEC. Acerca disso, observemos o excerto que segue:

Assim, esta CONAES, entende que o NDE é um bom indicador da qualidade de um curso de graduação e um elemento de diferenciação quanto ao comprometimento da instituição com o bom padrão acadêmico.

Ao se dispor do sintagma nominal "esta CONAES", por meio de formas verbais na voz ativa, o colegiado dá voz à instituição, para que o interlocutor compreenda o enunciado como uma manifestação de opinião do coletivo acerca da relevância do Núcleo Docente Estruturante no âmbito dos cursos de graduação como forma de garantir seu desenvolvimento. Nesse sentido, não é um relator que emite seu parecer acerca da questão, mas sim os membros do colegiado como um todo que se engendram em uma relação valorativa com o discurso. Assim, como agente que mobiliza a produção do enunciado, é a CONAES quem fala, assumindo o papel de apresentar a sua posição axiológica acerca do tema tratado, desempenhando, desse modo, sua função de enunciadora do discurso, que se envolve com o que diz e para quem diz. Assim sendo, temos, de um lado, a voz do MEC, como visto anteriormente; de outro, a voz da CONAES e não a voz de um ou dois relatores que assumem a autoria do texto.

Como a principal característica do gênero discursivo é o seu endereçamento a um interlocutor sócio-historicamente situado em um contexto (BAKHTIN, 2011), essa posição assumida pela CONAES no Parecer, como a voz institucional que fala, revela a intenção do órgão que é marcar a sua função social como a autoridade, responsável pela regulação da educação superior, diante do seu interlocutor (os diversos segmentos das comunidades acadêmicas), a fim de gerar certa reação: colocar em prática a sua exigência. 
Em outros termos, a "palavra”, no texto, se apresenta não na qualidade de opinião de um ou dois relatores que precisam da aprovação de seus pares (primeiramente) e da aceitação da comunidade acadêmica, mas sim procura assumir a atitude ideológica do órgão em relação ao tema tratado, surgindo como "palavra autoritária", que se liga ao "passado hierárquico" do órgão (BAKHTIN, 2014, p. 143). Temos, portanto, dois esteios que sustentam a opinião defendida no texto: a voz do MEC e a voz da CONAES, que se apresentam como argumento de autoridade. Não há, desse modo, o que contestar: as instituiçôes, querendo ou não, deverão criar um grupo de docentes responsável pela condução do curso.

Ainda no plano linguístico, constata-se que o posicionamento da CONAES acerca do NDE é introduzido pelo conectivo "assim" revelando uma confirmação de algo que foi dito antes. A discussão travada anteriormente refere-se à existência de colegiado nas estruturas administrativas dos cursos de graduação que, conforme o Parecer, "se ocupa das questôes do curso, inclusive do PPC, coordenado pelo Coordenador do Curso. É o que se convencionou chamar de Colegiado de Curso, ainda que receba nomes diversos em diferentes instituições". Por que trazer para o Parecer o discurso acerca do colegiado de curso e seu papel social? Bakhtin (2011, p. 302) pode nos fornecer uma resposta ao afirmar que,

Ao construir o meu enunciado, procuro defini-lo de maneira ativa; por outro lado, procuro antecipá-lo, e essa resposta antecipável exerce, por sua vez, uma ativa influência sobre o meu enunciado (dou resposta pronta às objeçôes que prevejo, apelo para toda sorte de subterfúgios, etc).

Sob essa ótica, podemos entender que, pensando ainda na "ação responsiva" de seus interlocutores, a CONAES antecipa a discussão acerca da existência do colegiado de curso no âmbito dos cursos de graduação com intuito de garantir seu posicionamento acerca da relevância do Núcleo Docente Estruturante como "indicador de qualidade do curso" e "elemento de diferenciação quanto ao comprometimento da instituição com o bom padrão acadêmico". O órgão admite a importância do colegiado de curso, mas destaca que este se ocupa de funções administrativas. Daí a necessidade de uma nova estrutura dentro do curso, no caso, o Núcleo Docente Estruturante para "elevar seus padrões de qualidade":

O Colegiado de Curso tende a ter um papel administrativo muito forte, resolvendo questões que vão desde a definição das necessidades de 
professores para atenderem disciplinas até a simples emissão de atestados, passando pela administração ou acompanhamento do processo de matrícula. Tais funções são necessárias, mas, sem dúvida, normalmente se sobrepõem à necessária reflexão sobre a qualidade acadêmica do curso. (...)

Este raciocínio nos leva a entender que o trabalho do colegiado de curso (assim como da sua coordenação) não pode ser confundido com o papel de um núcleo docente estruturante. Ambos podem ser exercidos pelas mesmas pessoas, mas normalmente não o são, e isso até enriquece o processo.

Circunscrita no processo da interação verbal, essa explicação constituise de respostas antecipadas (discurso-resposta futuro) a possíveis reações de objeção que as instâncias acadêmicas poderiam contrapor a seu discurso, devido ao fato de existirem dois organismos (NDE e Colegiado de Curso) responsáveis pelo projeto pedagógico de um curso de graduação. Com essa estratégia discursivo-argumentativa, o sujeito-autor vai construindo seu objeto discursivo, expondo seu ponto de vista, preocupando-se, todavia, com a reação-resposta ativa de seus interlocutores (BAKHTIN, 2011).

A voz da CONAES instiga-nos a analisar melhor o lugar social de onde ela fala, bem como sua orientação valorativa acerca do Núcleo Docente Estruturante, evidente na materialidade linguística, como vemos abaixo:

Do ponto de vista da avaliação, objeto desta CONAES, trata-se de um conceito que realmente poderá contribuir não só para a melhora do processo de concepção e implementação do projeto pedagógico de um curso de graduação, mas também no desenvolvimento permanente dele, com vista a sua consolidação.

Observamos que a CONAES deixa transparecer a imagem de si ("do ponto de vista da avaliação, objeto desta CONAES”), antes de apresentar sua avaliação sobre o papel social do Núcleo Docente Estruturante. Desse modo, quem considera o NDE "um conceito que realmente poderá contribuir" para a melhora do curso não é qualquer sujeito, mas sim um órgão que supervisiona e coordena o Sistema Nacional de Avaliação da Educação Superior (SINAES), cujo objeto é a avaliação da educação superior. Isso lhe garante autoridade para tecer sua posição avaliativa acerca da questão. Constatamos, ainda, em sua apreciação o uso do advérbio "realmente", o qual indica a presença do discurso de outrem no enunciado, concedendo-lhe uma avaliação positiva sobre o que foi dito. Nesse caso, o discurso já-dito 
é o discurso do MEC exposto na introdução do enunciado, em forma de discurso direto, como já mencionado. Apresentado logo na sequência do parágrafo introdutório, o fragmento evidencia a orientação axiológica da CONAES em harmonia com o discurso já-dito: a importância da criação do Núcleo Docente Estruturante.

Também percebemos no excerto acima o uso do recurso da nomeação para tratar do Núcleo Docente Estruturante, caracterizado como um "conceito criado". Ao longo do texto, tal núcleo também é qualificado como "alma do curso" e "elemento diferenciador da qualidade do curso". As qualificações atribuídas ao núcleo revelam o consenso em relação ao discurso do MEC, objetivando convencer os interlocutores acerca da relevância do NDE para todos os cursos de graduação. No trecho abaixo, ouvimos explicitamente o tom valorativo do enunciador com vistas a convencer o leitor a aceitar o seu ponto de vista:

A ideia surge da constatação de que um bom curso de graduação tem alguns membros do seu corpo docente que ajudam a construir a identidade do mesmo.

(...)

Entende-se, então, que todo curso que tem qualidade possui (ainda que informalmente) um grupo de professores que, poderia dizer, é a alma do curso. Em outras palavras, trata-se de um núcleo docente estruturante.

Os elementos linguísticos apreciativos tais como "um bom curso de graduação" e "curso que tem qualidade" são utilizados pelo sujeito-autor como estratégia para apresentar suas ideias como se fossem verdades, na medida em que, conforme o fragmento, a qualidade de um curso está condicionada à existência de um grupo de professores responsáveis pela sua condução.

Assim, com a reenunciação da voz do MEC, funcionando como coautoria; com a apresentação da CONAES como voz de autoridade, que expõe o ponto de vista do colegiado como um todo e com o uso de estratégias discursivo-argumentativas diversas, como vimos, espera-se que as Instituiçỗes de Educação Superior (IES) e demais interlocutores tenham se convencido da necessidade da criação de um "grupo de professores que, poder-se-ia dizer, é a alma do curso". Nesse ponto, cabe, então, ao sujeitoautor levar seus interlocutores, as IES, a abraçarem a causa defendida. E isso é feito com maestria no Parecer, visto que no fio do discurso empreendido, o enunciador discursivo, ao final do texto, delega a elas a função de definirem 
"as atribuições do NDE, ficando claro que não podem ser confundidas com as do Colegiado do Curso". E determina que:

Para a institucionalização do NDE, as IES, através dos seus colegiados superiores, devem definir sua constituição, de acordo com os critérios (composição, titulação dos membros, tempo de dedicação e de permanência sem interrupção, etc.) estabelecidos nos instrumentos aplicados pelo INEP para avaliação de cursos de graduação.

Com isso, apesar de ressaltar no texto que o "NDE deve ser considerado não como exigência ou requisito legal, mais [sic] como elemento diferenciador da qualidade do curso", a CONAES amarra a questão da obrigatoriedade da criação do NDE, visto que os instrumentos de avaliação aplicados pelo Instituto Nacional de Pesquisas Educacionais Anísio Teixeira (INEP) passariam a considerar esse órgão colegiado como base dos processos avaliativos, especialmente os atos de regulação dos cursos.

Desse modo, ao recuperar os critérios para a constituição do NDE, o enunciador consolida seu posicionamento, trazendo em sua enunciação a voz do INEP, que criaria os instrumentos de avaliação dos cursos de graduação. Faz-se aqui importante ressaltar que os critérios de análise, referentes à atuação do NDE nos cursos, seriam criados pelo INEP, conforme o disposto na Resolução CONAES n. 1/ 2010, oriunda do Parecer CONAES n. 4/2010, objeto deste estudo. Portanto, o enunciado do INEP entraria na relação dos enunciados da CONAES, baseando-se neles, apresentando-se, assim, como "elo na corrente complexamente organizada de outros enunciados" (BAKHTIN, 2011, p. 272). Diante disso, parafraseando o nosso teórico russo, o discurso da CONAES tem, no mínimo, dupla expressão: a sua (que também é alheia), e a expressão do enunciado que acolheria esse discurso, no caso, o INEP (BAKHTIN, 2011, p. 299).

\section{Considerações finais}

Neste artigo, trabalhamos conceitos teóricos dos estudos bakhtinianos, a fim de analisar o Parecer CONAES n. 4/2010. No percurso do trabalho, realizamos o estudo em dois momentos correlacionados entre si: um orientado para as condiçôes de produção do Parecer, bem como sua "estabilidade relativa"; outro, para a parte socioverbal e ideológica do enunciado na relação com as reflexóes levantadas na primeira parte. 
A análise do Parecer, sem deixar de lado o seu contexto enunciativo, objetivou garantir a perspectiva metodológica proposta por Bakhtin/ Volochínov (2014), para quem a análise deve-se iniciar pelo contexto e seguir em direção ao texto. Essa percepção é esclarecida por Brait (2006, p. 59) quando afirma que é na imbricação imanente entre o linguístico e o não linguístico que a análise deve ocorrer, visto que "excluir um dos polos é destruir o ponto de vista dialógico, proposto e explicitado pela teoria e pela análise, e dado como constitutivo da linguagem".

No que tange à análise da estrutura composicional, o objetivo não foi analisá-la como tal, mas sim buscar uma interpretação para a causa da sua mudança (considerando o Regimento Interno da CONAES), relacionando-a com a finalidade do discurso. Entendemos que a alteração ocorreu devido à intenção discursiva do enunciador que visava "estabelecer", "mandar fazer" algo, tendo de outro lado um destinatário que estaria na posição de "dever fazer", amarrando a questão com a elaboração de uma resolução para normatizar tal decisão. Isso difere da intenção discursiva de um parecer que vise "tecer considerações sobre questōes submetidas à apreciação do colegiado", em que os destinatários imediatos sãos os pares do relator do enunciado, que estão na posição de aprovar ou não as ideias nele defendidas.

Tendo em vista sua intenção discursiva, a CONAES se faz presente no Parecer, expondo a voz do colegiado como um todo. Assim, vimos que ela, como voz de autoridade, assumiu o papel de apresentar a sua posição axiológica acerca da criação do Núcleo Docente Estruturante no âmbito das instituições, "endereçando" seu discurso aos membros das instâncias acadêmicas, que deveriam criar o referido núcleo. A enunciação, desse modo, foi realizada a fim de gerar certa reação nos interlocutores, no sentido de levá-los a cumprirem a exigência. Assim, um parecer como nos moldes descritos no regimento interno do órgão (BRASIL, 2005) que tem como destinatário primeiro os membros do colegiado, não atenderia a intenção discursiva do enunciador.

Além disso, discorremos também sobre a influência da reação presumida do interlocutor na orientação do posicionamento axiológico do sujeito enunciativo, evidente nas estratégias discursivo-argumentativas. Vimos que, na trama do discurso, o sujeito enunciativo reenuncia discursos já-ditos, recorrendo à voz do Ministério da Educação para legitimar seus pontos de vista e enuncia o discurso-resposta futuro, explicitando, por exemplo, a diferença do trabalho do Colegiado de Curso e papel do Núcleo 
Docente Estruturante. Nesse sentido, antecipa possíveis reações-respostas de seus interlocutores, devido ao fato de existirem duas estruturas colegiadas (Núcleo Docente Estruturante e Colegiado de Curso), responsáveis pelo Projeto Pedagógico de um curso de graduação.

Diante da discussão certificamos, como entende Medviédev (2012, p. 195), que o Parecer CONAES n. 04/2010 se orienta, em primeiro lugar, para seus destinatários e para determinadas condiçôes de realização e de percepção. Isso porque toda obra "pressupõe um ou outro auditório de receptores ou leitores, esta ou aquela reação deles, esta ou aquela relação entre eles e o autor". Em segundo lugar, está orientado "na vida, como se diz, de dentro, por meio de seu conteúdo temático".

É nessa atmosfera que o sujeito enunciativo do Parecer CONAES N. 04/2010, ocupando um "certo lugar, que é concedido pela vida" (MEDVIÉDV, 2012, p. 195) e influenciado pela reação presumida de seus interlocutores, se constitui discursivamente, assimilando vozes e, ao mesmo tempo, suas inter-relações dialógicas, produzindo um enunciado que traduz o dialogismo da língua viva.

\section{Agradecimentos}

Registramos aqui os melhores agradecimentos ao Conselho Nacional de Desenvolvimento Científico e Tecnológico (CNPq) pela concessão da bolsa de doutorado.

\section{Referências}

AMORIM, M. Cronotopo e exotopia. In: BRAIT, B. Bakhtin: outros conceitoschave. São Paulo: Contexto, 2008.

BAKHTIN, M. O autor e a personagem na atividade estética. In: . Estética da criação verbal. Tradução de P. Bezerra. 6. ed. São Paulo: Martins Fontes, 2011. p. 34-192. [1920/1922].

BAKHTIN, M. O discurso no romance. In: Questôes de literatura e de estética: teoria do romance. Trad. A. F. Bernardini et alli. 6. ed. São Paulo: Hucitec, 2014 [1934-1935].

BAKHTIN, M. Gêneros do discurso. In: BAKHTIN, M. Estética da criação verbal. Trad. Paulo Bezerra. 6. ed. São Paulo: Martins Fontes, 2011. p. 261-306. [19521953]

BAKHTIN, M. Problemas da poética de Dostoiévski. Trad. Paulo Bezerra. 4. ed. ampliada. Rio de Janeiro: Forense Universitária, 2013 [1963]. 
BAKHTIN, M.; VOLOCHÍNOV, V. N. Marxismo e filosofia da linguagem: problemas fundamentais do método sociológico na ciência da linguagem. Trad. M. Lahud e Y. F. Vieira. São Paulo: Hucitec, 2014. [1929].

BRAIT, B. Uma perspectiva dialógica de teoria, método e análise. Gragoatá. Publicação de Pós-Graduação em Letras da Universidade Federal Fluminense. Niterói, n. 20, p. 47-62. $1^{\circ} \mathrm{sem}, 2006$.

BRAIT, B. Análise e teoria do discurso. In: BRAIT, B. Bakhtin: outros conceitoschave. São Paulo: Contexto, 2008.

BRAIT, B.; MELO, R. Enunciado/enunciado concreto/enunciação. In: BRAIT, B. (Org). Bakhtin: conceitos-chave. 5. ed. São Paulo: Contexto, 2012.

BRASIL. Lei n. 10.861 de 14 de abril de 2004, institui o Sistema Nacional de Avaliação da Educação Superior - SINAES. Disponível em: <http://www. presidencia.gov.br/legislaçao >. Acesso em: 2 out. 2014.

BRASIL. Lei n. 9.131, de 25 de novembro de 1995, institui o Conselho Nacional de Educação - CNE. Disponível em: <http://portal.mec.gov.br/index.php?Itemid=75 4\&catid=323\%3Aorgaos-vinculados\&id=14306\%3Acne-historico\&option=com content\&view=article $>$. Acesso em: 21 nov. 2014

BRASIL. Portaria n. 930, de 18 de março de 2005, aprova o Regimento Interno da Comissão Nacional de Avaliação da Educação. Disponível em: <http://portal.mec. gov.br/index.php?option=com_content\&view=article\&id=15712\&Itemid=1093> . Acesso em: 2 out. 2014

BRASIL. Portaria ministerial n. 147, 2 de fevereiro de 2007, dispõe sobre a complementação da instrução dos pedidos de autorização de cursos de graduação em direito e medicina. Disponível em: <http://portal.mec.gov.br/index. php? Itemid=86\&id=13034\&option=com_content\&view=article $>$. Acesso em: 2 out. 2014.

BRASIL. Parecer CONAES n. 04, de 17 de junho de 2010, sobre o Núcleo Docente Estruturante. Brasília, 2010. Disponível em: <http://portal.mec.gov.br/index. php?option=com_content\&view=article\&id=15712\&Itemid=1093>. Acesso em: 2 out. 2014.

BRASIL. Resolução n. 01, de 17 de junho de 2010, normatiza o Núcleo Estruturante e dá outras providências. Disponível em: <http://portal.mec.gov.br/index. php?option=com_content\&view=article\&id=15712\&Itemid=1093 $>$. Acesso em: 2 out. 2014.

CURY, C. R. J. Conselhos de Educação: fundamentos e funções. Revista Brasileira de Política e Administração da Educação - RBPAE. v. 22, n. 1, p. 41-67, jan./jul. 2006. Disponível em: <http://seer.ufrgs.br/index.php/rbpae/article/view/18721/10944>. Acesso em: 7 mar. 2016. 
FARACO, C. A. Linguagem e diálogo: as ideias linguísticas do círculo de Bakhtin. Curitiba: Criar, 2009.

KASPARY, A. J. Redação oficial: normas e modelos. 18a ed. Porto Alegre: Edita, 2007.

MEDVIÉDEV, P. N. O método formal nos estudos literários: introdução crítica a uma poética sociológica. Trad. Sheila Camargo Grillo e Ekaterina Vólkova Américo. São Paulo: Contexto, 2012 [1928].

PONZIO, A. A revolução bakhtiniana. Tradução de Valdemir Miotello et al. São Paulo: Contexto, 2011.

TODOROV, T. Mikhaïl Bakhtine: le principe dialogique. Paris: Édition du Seuil, 1981.

VIANNA, R. Marxismo e filosofia da linguagem à luz d'A ideologia alemã. Bakhtiniana, São Paulo, v. 1, n. 3, p. 29-41, 2010. Disponível em: <http://revistas. pucsp.br/index.php/bakhtiniana/article/view/3368/2238>. Acesso em: 2 mar. 2016.

VOLOSHINOV, V. N. Discurso na vida e discurso na arte (sobre a poética sociológica). Tradução de C. A. Faraco e C. Tezza [para fins didáticos]. Versão da língua inglesa de I. R. Titunik a partir do original russo, 1926.

Data de submissão: 07/08/2015. Data de aprovação: 09/05/2016. 
